\title{
Reforma do Ensino Médio e Gestão Escolar da escola pública em Minas Gerais: que parâmetros?
}

\section{High School Reform and Public-School Management in Minas Gerais: what parameters?}

\author{
Iracema Campos Cusati ${ }^{1 *}$, Neide Elisa Portes dos Santos ${ }^{2}$, Raphael Campos Cusati ${ }^{3}$
}

\section{RESUMO}

O presente artigo propõe uma reflexão a partir dos resultados de uma pesquisa bibliográfica, documental e de campo de abordagem qualitativa-descritiva que se encontra em desenvolvimento cujo objeto de estudo é o projeto proposto pelo governo do estado de Minas Gerais voltado à implementação da reforma do Ensino Médio instituída pela Lei Federal no. 13.415 de 16 de fevereiro de 2017. Baseada na noção de qualidade, a reforma proposta coloca centralidade na flexibilização curricular e no aumento da carga horária mínima para 1.000 horas anuais (frente às atuais 800 horas). Nessa perspectiva, o governo mineiro propõe uma forma de gestão por ele denominada compartilhada a ser desenvolvida, através de um projeto que recebeu o nome de SOMAR. Cabe ressaltar que essa forma de gestão será compartilhada com as chamadas Organizações da Sociedade Civil (OSC) sem fins lucrativos. Além do caráter reducionista da proposta da reforma que estabelece uma relação direta entre os problemas da qualidade do ensino, currículo e carga horária, a proposta desconsidera a influência das desigualdades sociais que afetam as trajetórias escolares da juventude brasileira. Nesse sentido, há que se considerar a transferência de recursos públicos para a iniciativa privada e as mudanças nas relações de trabalho que tendem a se precarizar, sobretudo, considerando o trabalho docente e o trabalho do gestor à medida que, ao transferir a gestão de três escolas para as OSC, confere a elas a prerrogativa de contratar pessoal.

Palavras-chave: Ensino Médio; Educação Profissional; Trabalho docente; Gestão educacional; Qualidade do ensino.

\section{ABSTRACT}

This article proposes a reflection based on the results of a bibliographical, documentary and field research with a qualitative-descriptive approach that is under development, whose object of study is the project proposed by the government of the state of Minas Gerais aimed at implementing the reform of the Secondary Education instituted by Federal Law no. 13,415 of February 16, 2017. Based on the notion of quality, the proposed reform places centrality in curricular flexibility and in increasing the minimum workload to 1,000 hours per year (compared to the current 800 hours). From this perspective, the Minas Gerais government proposes a form of management that it calls shared to be developed, through a project called SOMAR. It should be noted that this form of management will be shared with the so-called nonprofit Civil Society Organizations (CSOs). In addition to the reductionist character of the reform proposal, which establishes a direct relationship between the problems of teaching quality, curriculum and workload, the proposal disregards the influence of social inequalities that affect the school trajectories of Brazilian

\footnotetext{
${ }^{1}$ Universidade de Pernambuco - UPE Campus Petrolina.

*E-mail: iracema.cusati@gmail.com

${ }^{2}$ Universidade do Estado de Minas Gerais - UEMG

${ }^{3}$ Faculdade de Viçosa - Minas Gerais
} 
youth. In this sense, it is necessary to consider the transfer of public resources to the private sector and the changes in work relationships that tend to become precarious, above all, considering the teaching work and the manager's work as, when transferring the management of three schools for CSOs, gives them the prerogative to hire staff.

Keywords: High school; Professional education; Teaching work; Educational management; Teaching quality.

\section{INTRODUÇÃO}

O presente artigo pretende apresentar algumas reflexões iniciais a partir dos resultados de uma pesquisa bibliográfica, documental e de campo de abordagem qualitativa-descritiva que se encontra em desenvolvimento cujo objeto de estudo é o projeto proposto pelo governo do estado de Minas Gerais voltado à implementação da reforma do Ensino Médio instituída pela Lei Federal no. 13.415 de 16 de fevereiro de 2017 - projeto Somar.

No caso de Minas, as primeiras ações estão voltadas à ampliação da carga horária anual para 1.000 horas (frente às atuais 800 horas anuais) e ao desenvolvimento de medidas que visam à melhoria da qualidade da educação no Ensino Médio via flexibilização curricular. Sob a égide de um Ensino Médio atrativo para os estudantes, que atenda aos seus anseios e apresente melhores indicadores educacionais, a perspectiva anunciada nas proposições do Projeto Somar são voltadas a mudanças na gestão da escola pública estadual mineira através do desenvolvimento de estratégias baseadas no pluralismo de ideias e concepções pedagógicas que possam aditar a proposta da Secretaria de Estado de Educação de Minas Gerais (SEE/MG), a partir de 2022.

A implementação da iniciativa ocorre, neste primeiro momento, em três unidades públicas estaduais de ensino de Belo Horizonte e da região metropolitana com foco em um novo modelo de gestão denominado compartilhada, tendo como base o Currículo Referência do Ensino Médio de Minas Gerais.

As discussões sobre a democratização da gestão da escola pública se manifestaram a partir da década de 1980, sob a influência do processo de redemocratização do Brasil, que saía de uma ditadura. As formas mais comuns de provimento do cargo nas escolas públicas brasileiras dos anos de 1980 compreendiam algumas categorias, entre elas a escolha por meio de eleição direta que é considerada a mais próxima da gestão democrática.

O propósito do presente texto é o de apresentar alguns resultados da pesquisa em desenvolvimento que tem como objetivo, analisar o processo de implementação do Projeto Somar em Minas Gerais. 


\section{OBJETIVOS DA INVESTIGAÇÃO}

A promoção pelo estado de Minas Gerais de ações voltadas a reformas (de Estado e educação) não é recente. Entretanto, a partir dos anos 1990, tais ações ganham maior ênfase. (OLIVEIRA,1999); (SANTOS,2014). O que se observa é que, mesmo em casos em que o foco específico não é a educação, as reformas de Estado, tendem a promover mudanças significativas na área educacional. Como exemplo desse processo, citamos a chamada política do Choque de Gestão e Acordo de Resultados que afetou sobremaneira, tanto a educação básica, quanto a superior. Nesse processo, para a educação superior, foram adotadas medidas voltadas a avaliação de desempenho de professores baseada em resultados não apenas individuais, como também, institucionais, sendo que os resultados dessas últimas seriam aferidos pelo cumprimento de algumas metas e pela economia de insumos básicos como: água, luz, telefone, além de corte de pessoal. Os resultados obtidos pelas instituições, no caso, órgãos públicos, serviriam de base de cálculo para o percentual que o servidor faria jus em termos de gratificação - o seu salário multiplicado pelo resultado obtido em termos de porcentagem (de 0 a 100\%). O servidor só faria jus à gratificação, se obtivesse no mínimo 70\%, ou seja, 70 pontos. (SANTOS, 2014; SANTOS e VIEIRA, 2015).

Nesse sentido, pode-se dizer que, ao longo dos anos, no cenário mineiro, a educação de um modo geral, vem passando por reformas que visam à adequação do Estado e da administração pública aos pressupostos da modernização administrativa, haja vista a implementação da qualidade total nos anos 1990 na rede pública do estado. Além disso, a educação básica tem sido considerada estratégica para o desenvolvimento econômico.

Em face do exposto, o objetivo da investigação em curso é analisar o processo de implementação do Projeto Somar na Rede Pública Estadual de Minas Gerais.

Tal objetivo se desdobra nos seguintes objetivos específicos: identificar os pressupostos norteadores do projeto Somar; analisar como se estrutura o trabalho do gestor escolar a partir da sua implementação e identificar seus efeitos na organização do trabalho escolar.

\section{ITINERÁRIO METODOLÓGICO}

A investigação é de cunho qualitativo, com apresentação analítica e descritiva das informações encontradas pelas pesquisas bibliográfica, documental e de campo.

Em relação ao Projeto Somar, o desenvolvimento da experiência como piloto com vigência até dezembro de 2025, tem inspiração nas Charter schools. O mencionado projeto tem por base um modelo que prevê unidade de educação relativamente autônoma com gestão privada, embora financiada com recursos públicos. 
Esse modelo, designado escola charter é caracterizado por ações independentes e privadas de escolas públicas que, a baixo custo e desonerando o cidadão, propõe aproximar o ensino e a qualidade das escolas particulares das escolas públicas, sem interferir na gratuidade e disponibilidade para qualquer estudante mineiro.

Inicialmente, as escolas analisadas são as instituições nas quais o projeto será desenvolvido (três como experiência piloto) que se localizam na região metropolitana de Belo Horizonte - duas na própria cidade e uma no município de Sabará.

Os sujeitos da pesquisa são gestores educacionais vinculados às chamadas organizações sociais da sociedade civil e os gestores e docentes das instituições referenciadas acima que compõe o universo da pesquisa.

Como estratégia de pesquisa de campo, serão aplicados questionários e realizadas entrevistas semiestruturadas com gestores das entidades; docentes do programa; equipe pedagógica e docentes.

Os questionários terão por finalidade conhecer o perfil, o processo de trabalho e as condições de trabalho dos sujeitos da pesquisa.

Com vistas ao aprofundamento de algumas questões, serão realizadas entrevistas semiestruturadas com questões que permitam conhecer melhor a realidade dos gestores e docentes envolvidos no projeto considerando que a promoção da gestão democrática depende muito da disposição de todos que trabalham na escola para dialogar sobre os problemas cotidianos vividos por ela, ou seja, depende da prática, implica aprendizados da parte de todos os envolvidos, de pautas de discussão e de produção de argumentações demandadas num processo de construção, que é social.

\section{O ENSINO MÉDIO NA LEGISLAÇÃO BRASILEIRA: breve panorama}

No Brasil, houve, nos anos 1970, uma reforma da Lei 4024/61 pela Lei 5692/71 que entre outras ações, modificou a estrutura do ensino passando a utilizar as nomenclaturas ensino de $1^{\circ}$ grau (substituindo o primário e ginasial) e $2^{\circ}$ grau com três anos de duração.

A ampliação da escolaridade para oito anos de alguma maneira, representou um relativo processo de democratização da educação ${ }^{4}$, pelo menos em termos de acesso. Entretanto, a democratização do acesso não assegurou necessariamente as condições de permanência, uma vez que havia repetência e evasão escolar.

\footnotetext{
${ }^{4} \mathrm{O}$ processo de democratização na educação é entendido como o processo por meio do qual as forças sociais organizadas se mobilizam e lutam por espaços de participação, controle e decisão dos rumos das políticas educacionais no Brasil.
} 
Cabe ressaltar que a instituição da profissionalização compulsória no nível de $2^{\circ}$ grau trouxe algumas implicações para a estrutura da educação ${ }^{5}$.

Em relação às mudanças no ensino de $2^{\circ}$ grau nos anos 1970, de acordo com Cunha (2014, p. 914-915),

Expressa na Lei no. 5.692, de 11 de agosto de 1971, pretensiosamente denominada Lei de Diretrizes e Bases do Ensino de $1^{\circ}$ e $2^{\circ}$ Graus, essa política consistiu na fusão dos ramos do $2^{\circ}$ ciclo do Ensino Médio (na nomenclatura então vigente). Por determinação dessa lei, o ensino secundário, o ensino normal, o ensino técnico industrial, o ensino técnico comercial e o ensino agrotécnico fundiram-se. Todas as escolas deveriam oferecer somente cursos profissionais - então chamados de profissionalizantes - destinados a formar técnicos e auxiliares técnicos para as mais diversas atividades econômicas. Os cursos exclusivamente propedêuticos, como o antigo colegial (clássico e científico), não teriam mais lugar nesse nível de ensino.

A profissionalização compulsória instituída sob o argumento da ruptura com a cisão de duas modalidades: a profissional para os menos favorecidos e a propedêutica para as classes mais favorecidas, tinha alguns pressupostos.

Em relação à política de educação profissional, Cunha (2014, p. 932) argumenta que:

A política de profissionalização universal e compulsória no ensino de $2^{\circ}$ grau não foi uma necessidade do sistema produtivo nem correspondeu à lógica interna do sistema educacional. Nesse caso, a incongruência foi flagrante. No que diz respeito à dimensão industrial da profissionalização, sempre tomada como exemplo, a formação de técnicos e auxiliares técnicos não correspondia às artes industriais do $1^{\circ}$ grau, pautadas mais pelo artesanato do que pela cultura fabril. Por outro lado, a ultra especialização de técnicos e auxiliares técnicos era incongruente com a concepção dos cursos de graduação, em nível superior, os quais, segundo a Lei n. 5.540/68, deveriam começar com um ciclo básico, de caráter geral, de modo a evitar a precoce opção pela carreira.

Ao longo do tempo, o Ensino Médio, denominado na 5692/71, de ensino de $2^{\circ}$ grau, vem sofrendo reformas e mudanças que, inclusive, se articulam com as reformas de Estado e econômicas.

Cabe lembrar que, em 1982, houve a publicação da Lei 7044 que retirou a obrigatoriedade da profissionalização compulsória.

Em relação às mudanças na educação, em especial no que concerne ao ensino de $2^{\circ}$ grau, passa a receber, na Constituição Federal de 1988, a nomenclatura Ensino Médio. Em seu texto original, a legislação estabelecia:

Art. 208. O dever do Estado com a educação será efetivado mediante a garantia de:

I - ensino fundamental, obrigatório e gratuito, inclusive para os que a ele não tiveram acesso na idade própria;

5 Em função da vinculação da formação profissional ao ensino de $2^{\circ}$ grau, atual Ensino Médio, nesse trabalho, embora tendo como foco o Ensino Médio, serão apresentadas algumas discussões sobre a educação profissional quando for pertinente a articulação entre ambas modalidades. 
II - progressiva extensão da obrigatoriedade e gratuidade ao ensino médio; (Brasil, 1988a)

Como se pode observar, na Constituição Federal de 1988, o Ensino Médio (anterior ensino de $2^{\circ}$ grau) ainda se encontrava em processo de ampliação da obrigatoriedade. Posteriormente, o texto da Lei de Diretrizes e Bases da Educação Nacional, Lei n.9394/96, reforçou, em sua versão original, a progressiva extensão da obrigatoriedade em consonância com os preceitos constitucionais.

Posteriormente, com as emendas constitucionais, o Art. 208 passa a ter a seguinte redação:

Art. 208. O dever do Estado com a educação será efetivado mediante a garantia de:

I - educação básica obrigatória e gratuita dos 4 (quatro) aos 17 (dezessete) anos de idade, assegurada inclusive sua oferta gratuita para todos os que a ela não tiveram acesso na idade própria; (Redação dada pela Emenda Constitucional $n^{\circ} 59$, de 2009) (Vide Emenda Constitucional no 59 , de 2009);

II - progressiva universalização do ensino médio gratuito; (Redação dada pela Emenda Constitucional no 14 , de 1996);

III - atendimento educacional especializado aos portadores de deficiência, preferencialmente na rede regular de ensino;

IV - educação infantil, em creche e pré-escola, às crianças até 5 (cinco) anos de idade; (Redação dada pela Emenda Constitucional n ${ }^{\circ} 53$, de 2006);

$\mathrm{V}$ - acesso aos níveis mais elevados do ensino, da pesquisa e da criação artística, segundo a capacidade de cada um;

VI - oferta de ensino noturno regular, adequado às condições do educando;

VII - atendimento ao educando, em todas as etapas da educação básica, por meio de programas suplementares de material didático escolar, transporte, alimentação e assistência à saúde. (Redação dada pela Emenda Constitucional $\mathrm{n}^{\circ} 59$, de 2009); subjetivo.

$\S 1^{\circ} \mathrm{O}$ acesso ao ensino obrigatório e gratuito é direito público

$\S 2^{\circ} \mathrm{O}$ não-oferecimento do ensino obrigatório pelo Poder Público, ou sua oferta irregular, importa responsabilidade da autoridade competente.

$\S 3^{\circ}$ Compete ao Poder Público recensear os educandos no ensino fundamental, fazer-lhes a chamada e zelar, junto aos pais ou responsáveis, pela freqüência à escola. (BRASIL, 1988b)

Como se pode observar, a Constituição após as emendas constitucionais, estabeleceu a progressiva universalização do Ensino Médio. Cabe lembrar que historicamente, essa etapa de ensino esteve vinculada à educação profissional. Aliás, a identidade do Ensino Médio por vezes se caracteriza como dual, devido à sua dupla possibilidade: função de formação profissional (preparação para o trabalho) ou preparação para estudos posteriores (propedêutica).

Em 1997, no governo Fernando Henrique Cardoso, houve a publicação de um Decreto, o de número 2208 que alterou a estrutura da educação profissional. Cabe ressaltar que tal reforma afetava a estrutura do Ensino Médio, reforçando a dualidade estrutural à medida que separava a formação em nível técnico da formação geral (Ensino Médio).

O referido Decreto estabeleceu três níveis de educação profissional: básico; técnico e tecnológico. A legislação em tela estabelece: 
Art $3^{\circ} \mathrm{A}$ educação profissional compreende os seguintes níveis:

I - básico: destinado à qualificação, requalificação e reprofissionalização de trabalhadores, independente de escolaridade prévia;

II - técnico: destinado a proporcionar habilitação profissional a alunos matriculados ou egressos do ensino médio, devendo ser ministrado na forma estabelecida por este Decreto;

III - tecnológico: correspondente a cursos de nível superior na área tecnológica, destinados a egressos do ensino médio e técnico. (BRASIL, 1997).

Como argumentado, a configuração da educação profissional delineada pelo referido Decreto reforça a dualidade do Ensino Médio à medida que retira a equivalência dessa modalidade de ensino com a educação profissional.

Posteriormente, durante o governo Lula, houve a revogação do Decreto de 1997. Mesmo tendo por base as críticas da separação entre educação profissional e o Ensino Médio, a reforma instituída no governo Luiz Inácio Lula da Silva foi vista como uma proposta, na compreensão de Frigotto; Ramos e Ciavatta (2005), marcada por um um percurso controvertido à medida que não considerou as contribuições de pesquisas acadêmicas da área de trabalho e educação nem mesmo os debates de algumas entidades. De acordo com os mencionados autores, a proposta do governo estava pautada em programas pontuais.

Apesar da tentativa de integração presente na proposta, a manutenção da política curricular anterior voltada ao Ensino Médio e à educação profissional, representaria, de acordo com Frigotto; Ramos e Ciavatta (2005), a manutenção das bases da proposta anterior que tinha, como referências, as dimensões das competências e da empregabilidade.

A tentativa de integração não teria sido bem sucedida em função da materialidade da política através de programas e projetos pontuais em que pese a revogação do Decreto n. 2208 de 1997.

No governo da Presidenta Dilma Rousseff, houve uma expansão da educação profissional. Destaca-se, nesse período, a criação do PRONATEC - Programa Nacional de Acesso ao Ensino Técnico e ao Emprego. ${ }^{6}$

De acordo com Lima e Pacheco (2017, p. 500),

As matrículas produzidas no âmbito do PRONATEC expressam sua magnitude e justificam a discussão em torno de suas ações. As matrículas totais do programa no período de 2011 a 2014 ultrapassaram oito milhões, e, destas, quase seis milhões foram para

\footnotetext{
${ }^{6}$ O PRONATEC, aprovado pela Lei no 12.513 , de 26 de outubro de 2011, incorpora várias ações anteriores à sua criação e institui o Bolsa Formação, iniciativa que visa à qualificação e à habilitação de trabalhadores e estudantes brasileiros, constituindo foco de disputa pelos recursos públicos. Esse programa é responsável por mais de 8,1 milhões de matrículas em cursos de Educação Profissional Técnica de Nível Médio (EPTNM) e de Formação Inicial e Continuada (FIC) de 2011 a 2014. Sua abrangência ultrapassou o número de 4.300 municípios brasileiros, envolvendo 15 ministérios do governo Dilma Rousseff e as redes pública e privada, e o programa movimentou mais de $\mathrm{R} \$ 14$ bilhões no mesmo período, conforme informações disponibilizadas no sítio do MEC. (LIMA e PACHECO, 2017, p. 491).
} 
cursos de curta duração - denominados decursos de FIC — e pouco mais de dois milhões para cursos de EPTNM.

Apesar de ter havido expansão da Rede Federal de Educação Profissional o que levou a um certo fortalecimento dessa modalidade de ensino, no que se ao refere Ensino Médio, a referida política apresentou algumas contradições. A ênfase na dimensão da formação continuada e em cursos de curta duração em detrimento da Educação Profissional de Nível técnico integrado ao ensino médio ou de nível tecnológico não possibilitaria, segundo Lima e Pacheco (2017), a articulação da formação profissional ao aumento da escolaridade da população - um dos problemas de uma desarticulação entre as modalidades e etapas do ensino. Cabe lembrar que essa uma das limitações da política delineada pelo Decreto 2208/1997.

Posteriormente, na vigência do governo Temer que sucedeu a Presidenta Dilma após ela sofrer um processo de impeachment, foi promulgada a Lei 13.415/2017 que tem sido questionada não somente em função do seu foco: a reforma do ensino pautada no currículo com vistas à melhoria da qualidade - o que representa uma visão reducionista de educação que despreza questões sociais importantes, como seu próprio processo de aprovação no contexto do governo de Michel Temer - sem debate. A Lei foi aprovada às pressas sem o debate necessário.

Em face dos aspectos discutidos a partir da incursão em algumas Leis e Decretos, podese inferir que o ensino médio, vem, ao longo da história passando por modificações que ora reforçam a dualidade, ora caminham no sentido de buscar superá-la. Observa-se igualmente, que mesmo em governos progressistas que buscam a democratização do acesso e permanência na educação, questões como a dualidade e o confronto entre o público e o privado ainda persistem.

No que concerne ao processo de implementação da Lei em vigor [a Lei n. 13.415/2017], no cenário mineiro, o governo de Minas está desenvolvendo algumas ações: a ampliação da jornada escolar, inicialmente, para $1.000 \mathrm{~h}$ anuais, conforme previsto para o primeiro ano. Posteriormente, está prevista a ampliação para $1.400 \mathrm{~h}$ anuais - ensino em tempo integral jornada de $7 \mathrm{~h}$ diárias. Para se alcançar inicialmente a ampliação de $800 \mathrm{~h}$ para $1.000 \mathrm{~h}$ anuais, o governo instituirá o sexto horário. Embora não seja foco da pesquisa, é importante salientar que essa medida, se não acompanhada de ações efetivas para assegurar as condições de permanência na escola, poderá reforçar os processos de exclusão da juventude que já enfrenta dificuldades para conciliar trabalho e emprego - um dos fatores que levam à evasão na última etapa da educação básica.

Para o cumprimento do processo de implementação do novo ensino médio, o governo mineiro, irá promover uma experiência piloto em três escolas da Rede Pública Estadual através do Projeto Somar cujo alguns aspectos serão apresentados a seguir. 


\section{OS CONTORNOS DO PROJETO SOMAR}

O Brasil, vem, desde os anos 1990, implementando reformas educacionais com vistas à melhoria da qualidade da educação. Cabe ressaltar que a noção de qualidade tem vários significados. Como foi apresentado no decorrer do trabalho, o estado de Minas Gerais constitui um exemplo expresso inclusive, pela implementação do Programa Qualidade Total nas escolas públicas de Minas Gerais nos anos 1990 com foco na redução da repetência escolar. (OLIVEIRA, 1999).

Como exemplo elucidativo da polissemia da noção de qualidade, citamos o próprio processo de reforma do ensino médio atual que focaliza a possibilidade de melhoria da educação e dos resultados educacionais no currículo escolar, desconsiderando outras dimensões importantes como as condições de permanência na escola.

Mais uma vez reportando ao caso mineiro, cabe lembrar que se encontra em curso, o projeto ora citado, o Somar, que se encontra em desenvolvimento como experiência piloto, como mencionado anteriormente. $\mathrm{O}$ processo de seleção das instituições executoras deu-se através de editais de chamada pública.

$\mathrm{Na}$ justificativa do Projeto, o governo argumenta que, mesmo as instituições sendo privadas, a educação continua sendo pública. Tal justificativa necessita de uma análise crítica, posto que, sob o de que a educação continua sendo pública, o estado transfere e deixa de aplicar recursos públicos os repassando para a iniciativa privada, assumindo o seu papel de Estado regulador e avaliador que irá monitorar os indicadores do ensino à distância, via inspeção escolar, modificando seu papel de provedor da educação pública.

Os objetivos declarados nas proposições do Projeto passam pela melhoria da qualidade do ensino médio traduzida em indicadores de avaliação; redução dos índices de evasão e a transformação dessa etapa de ensino em uma experiência mais atrativa aos estudantes. Como foi discutido, nessa linha argumentativa, são desconsideradas questões relacionadas às desigualdades sociais que afetam sobremaneira a permanência na escola. Cabe ressaltar que não estamos desconsiderando a importância das estratégias didáticas e outros processos que considerem os projetos de vida dos/as estudantes. É certo que o protagonismo juvenil se configura como um importante elemento que, ao lado de políticas sociais, podem contribuir para incentivar a permanência dos jovens nessa etapa de ensino. (ANJOS; CUSATI; SANTOS, 2021).

Do ponto de vista geral, a regulação educativa esboçada pelo projeto parece guardar uma convergência com os aspectos apresentados por Barroso (2006) referentes ao papel do Estado no contexto português - de avaliador, uma vez que, no caso de Minas Gerais estão previstas ações de monitoramento partindo de dois conceitos-chave: eficácia e efetividade. O primeiro se refere a ação de acompanhamento semestral da carga horária cumprida; percentual de estudantes que realizaram as avaliações internas e externas (SAEBE e PROEB). Seguindo a tendência de ênfase 
nos resultados, a noção de efetividade, segundo conceito-chave, aparece vinculada a indicadores de qualidade referenciados nos resultados apresentados pelos alunos nas avaliações acima citadas. Serão considerados com maior ênfase os resultados de desempenho em língua portuguesa e matemática; as taxas de aprovação; reprovação; abandono e satisfação da comunidade. Tais noções evidenciam a centralidade dos resultados na regulação da política.

Cabe salientar que já foi selecionada a Organização da Sociedade Civil (OSC) que irá executar o projeto - a mesma instituição ganhou os três lotes. A instituição selecionada é uma OSC sem fins lucrativos, conforme previsto nos editais; trata-se de uma instituição escolar da rede particular que oferece educação de nível técnico no estado da Bahia Trata-se da Associação do Centro de Educação Tecnológica do Estado da Bahia (CETEB). De acordo com informações veiculadas no site da instituição, "o colégio CETEB é uma escola de ensino médio fundada em 2016 e que tem como mantenedora, a Associação Centro de Educação Tecnológica do Estado da Bahia, Organização da Sociedade Civil, empresa privada sem fins lucrativos. Os valores defendidos como princípios da escola estão em consonância com os definidos pela escola e que norteiam as proposições da reforma do ensino médio - ênfase nos resultados atrelados a metodologias inovadoras e protagonismo juvenil.

Em que pese o fato de a instituição educacional selecionada ter um lastro na educação, há alguns aspectos que precisam ser teorizados e discutidos: a transferência de recursos públicos para a iniciativa privada; a visão reducionista do Estado de que o problema da evasão escolar se resume à atratividade equacionado por um currículo flexível; o recrudescimento do processo de fortalecimento das instituições privadas que receberão recursos públicos; o processo de seleção de pessoal só para selecionar alguns etc.

A partir da análise dos documentos norteadores do projeto, bem como da literatura que vem se debruçando sobre o processo de implementação do novo ensino médio Ferretti (2018); Kuenzer (2017), por exemplo, é possível se identificar elementos que convergem para a centralidade na melhoria dos resultados e dos indicadores educacionais com o foco na responsabilização de docentes e gestores.

Cabe lembrar que a instituição executora terá a prerrogativa de selecionar e contratar professores e gestores pelo regime celetista e tal processo corrobora com a lógica privatista que vem permeando a educação no Brasil.

\section{ALGUMAS CONSIDERAÇÕES}

O governo mineiro reproduz a tendência criticada por Ferretti (2018) e Kuenzer (2017) de reduzir os problemas de abandono a questões de atratividade que podem vir supostamente a ser equacionados por um currículo flexível, desconsiderando totalmente os problemas das 
desigualdades sociais e a realidade da classe trabalhadora - jovens que evadem da escola por não conseguirem conciliar trabalho e estudo.

A flexibilidade do processo de ensino e aprendizagem materializada pela proposta de um currículo flexível; a flexibilização dos processos de gestão combinado com a rigidez da avaliação e a flexibilidade de contratos - transferindo a gestão de pessoas para as OSC são questões sinalizadas num processo que está apenas se delineando - anunciado nos editais de chamada pública para a propalada parceria de gestão compartilhada compartilhada não com a comunidade, mas com a iniciativa privada (lembrando que, por enquanto, são apenas três escolas piloto).

A reforma do ensino médio proposta coloca ênfase na melhoria dos resultados educacionais apresentados pelos estudantes. Nesse sentido, cabe problematizar o caráter e os desdobramentos desse processo cuja a regulação educativa baseia-se em resultados. Esta forma de regulação e seus efeitos vêm sendo discutidos por autores como Augusto (2012) na educação básica; na educação superior, por Santos (2014) e Santos; Vieira (2015).

A gestão democrática da escola pública, embora tendo amparo legal, precisa se transformar em prática e, além disso, fazer dessa prática uma atividade sistemática tendo em vista o diálogo e a deliberação ocorridos de forma coletiva sobre questões que são importantes para o funcionamento da escola e para as pessoas que nela trabalham e estudam. Esse processo deve ser conduzido com ponderação e refeito pelas opiniões divergentes. Logo, a promoção da gestão democrática da escola pública implica dedicar tempo para a concretização de um processo de discussão e decisão.

Para esse ano (2022), o governo mineiro abriu processo de seleção para direção das escolas piloto do projeto Somar. Ainda que os pré-requisitos para a investidura nos cargos de diretor e vice-diretor (pedagógico e administrativo) sejam ser servidor efetivo e possuir formação na área de educação, há que se considerar que o cargo é comissionado sem a participação da comunidade no processo de escolha - o que já sinaliza mudanças no papel do gestor.

Fica sinalizada ainda a precarização do trabalho docente (ainda que temporário) e do trabalho do gestor até então, um professor/uma professora efetivo/a escolhido/a pela comunidade. Mesmo que pareça à primeira vista um ganho para o docente por ter as garantias trabalhistas da CLT, ainda está posta a precarização do trabalho. O cenário parece apontar, caso a proposta das OSC se consolide, para uma possível colocação de funcionários e docentes em disponibilidade disponível para outras instituições.

\section{REFERÊNCIAS}

ANJOS, Dayane Priscilla Bernardes; CUSATI, Iracema Campos; SANTOS, Neide Elisa Portes dos. Protagonismo juvenil nas escolas de referência em ensino médio: origem e repercussões no 
Município de Petrolina - PE. In: SILVA, C. B. da; ASSIS, Andrelize Shabo Ferreira de. (Orgs.). Vivências didáticas: metodologias aplicadas em ensino e aprendizagem. Rio de Janeiro: Publicar Editora, 2021, p.53-71.

BARROSO, João (Org). A definição das políticas públicas de educação: espaços, dinâmicas e actores. Lisboa: EDUCA e Unidade de I\&D em Ciências da Educação, 2006.

BRASIL. [Constituição (1988a)]. Constituição da República Federativa do Brasil de 1988: Nós, representantes do povo brasileiro, reunidos em Assembleia Nacional Constituinte para instituir um Estado Democrático, destinado a assegurar o exercício dos direitos sociais [...]. Diário Oficial da União, Brasília, ano 126, n. 191-A, 5 out. 1988. Disponível em: https://www2.camara.leg.br/legin/fed/consti/1988/constituicao-1988-5-outubro-1988-322142publicacaooriginal-1-pl.html. Acesso em: 22 jan. 2022.

BRASIL. [Constituição (1988b)]. Constituição da República Federativa do Brasil de 1988. Brasília, DF: [2020]. Disponível em:

http://www.planalto.gov.br/ccivil_03/constituicao/constituicao.htm. Acesso em: 22 jan. 2022.

BRASIL. Decreto $\mathbf{n}^{\circ} .2208$ de 17 de abril de 1997. Regulamenta o $\S 2^{\circ}$ do art. 36 e os arts. 39 a 42 da Lei $n^{\circ}$ 9.394, de 20 de dezembro de 1996, que estabelece as diretrizes e bases da educação nacional. Brasília, DF: [2004]. Disponível em:

http://www.planalto.gov.br/ccivil_03/decreto/d2208.htm. Acesso em: 22 jan. 2022.

BRASIL. Lei de Diretrizes e Bases da Educação Nacional de 20 de dezembro de 1961. Fixa as Diretrizes e Bases da Educação Nacional. Brasília, DF: Câmara dos Deputados. Disponível em:

https://www.google.com/url?sa=t\&source=web\&rct=j\&url=https://www2.camara.leg.br/legin/fe d/lei/1960-1969/lei-4024-20-dezembro-1961-353722-normaatualizada-

pl.pdf\&ved=2ahUKEwiVrOvJ2tf0AhUCppUCHQljD08QFnoECCkQAQ\&usg=AOvVaw30zw DD0UcfnhULVYCJWabw. Acesso em: 22 jan. 2022.

BRASIL. Lei ${ }^{\circ} .5 .692$ de 11 de agosto de 1971. Fixa Diretrizes e Bases para o ensino de $1^{\circ} \mathrm{e}$ $2^{\circ}$ graus, e dá outras providências. Brasília, DF; 1971. Disponível em:

https://presrepublica.jusbrasil.com.br/legislacao/128525/lei-de-diretrizes-e-base-de-1971-lei5692-71. Acesso em: 22 jan. 2022.

BRASIL. Lei $\mathbf{n}^{\circ} \mathbf{. 7 . 0 4 4}$ de 18 de outubro de 1982. Altera dispositivos da Lei ${ }^{\circ}$ 5.692, de 11 de agosto de 1971, referentes a profissionalização do ensino de $2^{\circ}$ grau. Disponível em: https://www2.camara.leg.br/legin/fed/lei/1980-1987/lei-7044-18-outubro-1982-357120publicacaooriginal-1-pl.html. Acesso em: 22 jan. 2022.

BRASIL. Lei de Diretrizes e Bases da Educação Nacional de 20 de dezembro de 1996. Estabelece as diretrizes e bases da educação nacional. Brasília, DF: [2009]. Disponível em: http://www.planalto.gov.br/ccivil_03/leis/19394.htm. Acesso em: 22 jan. 2022.

BRASIL. Lei $\mathbf{n}^{\circ} \mathbf{~ 1 3 . 1 4 5}$ de 16 de fevereiro de 2017. Altera as Leis $n^{\circ}$ 9.394, de 20 de dezembro de 1996, que estabelece as diretrizes e bases da educação nacional, e 11.494, de 20 de junho 2007, que regulamenta o Fundo de Manutenção e Desenvolvimento da Educação Básica e de Valorização dos Profissionais da Educação, a Consolidação das Leis do Trabalho - CLT, aprovada pelo Decreto-Lei $n^{\circ} 5.452$, de $1^{\circ}$ de maio de 1943, e o Decreto-Lei $n^{\circ} 236$, de 28 de fevereiro de 1967; revoga a Lei ${ }^{\circ} 11.161$, de 5 de agosto de 2005; e institui a Política de Fomento à Implementação de Escolas de Ensino Médio em Tempo Integral. Disponível em: http://www.planalto.gov.br/ccivil_03/_ato2015-2018/2017/lei/l13415.htm. Acesso em: 22 jan. 2022. 
CUNHA, Luiz Antônio. Educação profissional: o grande fracasso da ditadura. São Paulo: Cadernos de Pesquisa, v. 44, n. 154, p. 912-933, out.-dez./2014. Disponível em: https://doi.org/10.1590/198053142913. Acesso em: 04 jan. 2022.

FERRETTI, Celso J. A reforma do Ensino Médio e sua questionável concepção de qualidade da educação. São Paulo: Ensino de Humanidades Estud. Av., v. 32, n. 93, p. 25-42, mai-ago./ 2018. Disponível em: https://doi.org/10.5935/0103-4014.20180028. Acesso em: 04 jan. 2022.

FRIGOTTO, Gaudêncio; RAMOS, Marise; CIAVATTA, Mária. A política de educação profissional no Governo Lula: um percurso histórico controvertido. São Paulo: Campinas, Educação \& Sociedade, v. 26, n. 92, p. 1087-1113, out./2005. Disponível em: https://doi.org/10.1590/S0101-73302005000300017. Acesso em: 04 jan. 2022.

KUENZER, Acácia Zeneida. Trabalho e escola: a flexibilização do Ensino Médio no contexto do regime de acumulação flexível. São Paulo: Dossiê Educação \& Sociedade, v. 38, n. 139, p. 331-354, abr-jun./2017. Disponível em: https://doi.org/10.1590/ES0101-73302017177723. Acesso em: 04 jan. 2022.

LIMA, Marcelo; PACHECO, Zilka Sulamita Teixeira Aguiar. As Políticas Públicas e o direito à educação: Programa Nacional de Acesso ao Ensino Técnico e emprego versus Plano Nacional de Educação. São Paulo: Educação \& Sociedade, v. 38, n. 139, p. 489-504, abr-jun./2017. Disponível em: https://doi.org/10.1590/ES0101-73302017167752 Acesso em: 04 jan. 2022.

SANTOS, Neide Elisa Portes dos. Gestão e Trabalho na Universidade: as recentes reformas do Estado e da Educação Superior e seus efeitos no trabalho docente na UEMG. 2014. Tese (Doutorado em Educação). Universidade Federal de Minas Gerais, Programa de Pós- graduação em Educação - Conhecimento e Educação. Belo Horizonte.

SANTOS, Neide Elisa Portes dos; VIEIRA, Lívia Fraga. A (re) configuração do trabalho docente na Universidade do Estado de Minas Gerais frente às reformas de Estado e da Educação dos anos 2000. Rio Grande do Sul: Currículo sem Fronteiras, v. 15, n.2, p. 409-424, mai-ago./ 2015. Disponível em: http://www.curriculosemfronteiras.org/vol15iss2articles/santos-vieira.pdf. Acesso em: 04 jan. 2022.

OLIVEIRA, Dalila Andrade. As reformas em curso nos sistemas públicos de educação básica: empregabilidade e eqüidade social. In: OLIVEIRA, D. A.; DUARTE, M. R. T. (Orgs.).

Política e Trabalho na Escola: Administração dos sistemas públicos de Educação Básica. BH: Autêntica, 1999. p. 69-97. 